\title{
Cost Analysis of Blood Group and Antibody Screening for Emergency Appendicectomy: Should We Stop?
}

Ian S Farrell ${ }^{1}$, James Hall², James Hill ${ }^{3}$

\begin{abstract}
Introduction: The rate of transfusion associated with emergency laparoscopic general surgery has been shown to be $0.36 \%$. A significant number of patients undergo group and antibody screening due to perceived risk of hemorrhage. All NHS hospitals have massive transfusion policies with immediate availability of O-negative blood. Blood group and antibody screening carries a cost of $£ 35$. The aim of this study was to determine the cost-effectiveness of group and antibody screening vs crossmatching where required.

Materials and methods: All patients undergoing emergency appendicectomy over a 3-year period were retrospectively identified. The transfusion service then identified whether blood had been issued.

Results: A total of 645 emergency appendicectomies were identified: 603 were laparoscopic and 42 open. One (0.2\%) patient received a transfusion of 2 units.

Discussion: Our study has shown a rate of transfusion of $0.2 \%$. If patients were crossmatched as required rather than group and screening, this would give a cost saving of $£ 35$ per patient or $£ 22345$ across our trust. There are 50,000 appendicectomies per year in the United Kingdom. If this saving were extrapolated, it would generate a saving of $£ 1.1 \mathrm{M}$.

Conclusion: Our recommendation would be to crossmatch where required. The cost saving to the NHS could be up to $£ 1.1 \mathrm{M}$ with little impact on the demand for O-negative blood.

Keywords: Appendicectomy, Laparoscopy, Transfusion.

World Journal of Laparoscopic Surgery (2020): 10.5005/jp-journals-10033-1414
\end{abstract}

\section{INTRODUCTION}

The rate of blood transfusion associated with any form of laparoscopic general surgery is low. A recent single-center study looking at elective laparoscopic day case surgery revealed no transfusions in a 2-year period in 532-day case patients. ${ }^{1}$ Similarly, a study investigating transfusions during emergency laparoscopic appendicectomy, cholecystectomy, and diagnostic laparoscopy found the rate of transfusion to be less than $0.4 \%$ in the perioperative or immediate postoperative period (Day 1 postoperative) in 562 patients. $^{2}$

There is a perception that there is an increased risk of major hemorrhage during laparoscopic surgery from anesthetic and surgical staff, despite the evidence that transfusion rates are low. In addition to this, there is no national guidance on preoperative blood screening for emergency laparoscopic surgery. In our trust, it remains policy that patients undergoing emergency laparoscopic procedures have group and screen tests carried out prior to theater.

The purpose of group and screen is to screen for unusual antibodies and also to allow transfusion laboratories to store samples to crossmatch if blood is required. This test takes approximately 45 minutes. Blood crossmatch takes approximately 60 minutes before blood is available, this shows that there is no presence of unusual blood antibodies. ${ }^{3}$ For major hemorrhage scenarios, all NHS hospitals are required to have a massive transfusion policy with immediate O-negative blood availability in major hemorrhage scenarios. ${ }^{4}$ Conventional wisdom dictates that all perioperative transfusions should be type specific in order to minimize risk of transfusion reactions; however, transfusion of O-negative blood only carries a very low additional risk of nonABO-alloantibody incompatibility. Studies have shown an incidence
${ }^{1-3}$ Department of General Surgery, Manchester Royal Infirmary, Manchester, England, UK

Corresponding Author: lan S Farrell, Department of General Surgery, Manchester Royal Infirmary, Manchester, England, UK, e-mail: ian. farrell@doctors.org.uk

How to cite this article: Farrell IS, Hall J, Hill J. Cost Analysis of Blood Group and Antibody Screening for Emergency Appendicectomy: Should We Stop? World J Lap Surg 2020;13(3):128-129.

Source of support: Nil

Conflict of interest: None

of hemolytic transfusion reactions in only 1 in 70,000 O-negative transusions. $^{5}$

Routine blood group and antibody screening prior to surgery has an associated cost of approximately $£ 17.50$ per sample in our unit. The requirement for two samples prior to transfusion brings the cost of screening to $£ 35$ per patient.

The aim of this study was to determine the cost-effectiveness of blood group and antibody screening for appendicectomy compared to crossmatching as required together with the use of $\mathrm{O}$-negative blood when massive peri-operative transfusion is required.

\section{Materials and Methods}

All patients undergoing appendicectomy in our center over a 3-year period were retrospectively identified. All patients under 16 and all nonemergency cases were excluded. The patient records were examined to determine whether preoperative group and antibody

() The Author(s). 2020 Open Access This article is distributed under the terms of the Creative Commons Attribution 4.0 International License (https://creativecommons. org/licenses/by-nc/4.0/), which permits unrestricted use, distribution, and non-commercial reproduction in any medium, provided you give appropriate credit to the original author(s) and the source, provide a link to the Creative Commons license, and indicate if changes were made. The Creative Commons Public Domain Dedication waiver (http://creativecommons.org/publicdomain/zero/1.0/) applies to the data made available in this article, unless otherwise stated. 
screening had been requested. The transfusion laboratory then identified which of these patients had been issued blood in the perioperative or postoperative period and whether this was type specific or O-negative blood.

\section{Results}

A total of 645 emergency appendicectomies were identified of which 603 were laparoscopic cases and 42 open. There were 334 male and 311 female patients with a median age of 29 (range 16-83).

Of all 645 cases, $1(0.2 \%)$ patient received a blood transfusion ( 1 unit in recovery and 1 unit in the postoperative period). Both these units were type-specific blood following full crossmatch.

\section{Discussion}

In our study, in a cohort of 645 patients, we established that the incidence of perioperative transfusion was $0.2 \%$, comparable to the previously published rate of $0.36 \% .^{2}$ In our study, there were no massive transfusion events requiring O-negative blood. The one patient who required blood was able to wait for type-specific blood to be available.

At present, the National Transfusion Service charge the same for a unit of blood regardless of blood type (£132.72). ${ }^{6}$ It has been proposed that O-negative blood should attract an additional charge $^{6}(£ 180)$, the reason being that O-negative blood is the universal donor group and thus stocks of this should be protected. The differential charge would be to encourage use of type-specific blood where possible.

If blood products are required in the vast majority of cases, the use of blood products is an urgent clinical need but not an emergency requiring activation of a major hemorrhage protocol; in our study, no patients required an emergency transfusion. A wait of up to 60 minutes for blood to be available would not constitute a significant clinical risk. Not having a prior group and screen would add approximately 15 minutes to this process due to the need to sample blood and deliver it to the hematology laboratory. The risk of unexpected antibodies at group and screen is approximately $1.5 \%{ }^{7}$ Therefore, if $0.2 \%$ of cases require transfusion, the chance of a patient undergoing emergency appendicectomy needing blood and it not being available is negligible (0.003\%) (Tables 1 and 2 ).

If routine crossmatch was removed from our trust, this would have saved $£ 22,435$. It is estimated that there are approximately 50,000 emergency appendicectomies carried out in the United Kingdom every year. ${ }^{8}$ If our data were extrapolated to these 50,000 cases, then crossmatching when required rather than routinely group and antibody screening every patient would save $£ 1.1 \mathrm{M}$. Further advantages of this strategy are reducing burden on the blood transfusion service and to remove a potential delay in patient transfer to the theater whilst waiting for group and screen tests to be carried out, with the associated potential to increase morbidity from the condition. By transfusing O-negative blood in massive hemorrhage and carrying out crossmatch on an as-required basis,
Table 1: Total number of appendicectomies identified in our unit over a 3 year period and the surgical approach

\begin{tabular}{ll}
\hline Total emergency appendicectomies & 645 \\
Laparoscopic & $603(93 \%)$ \\
Open & $42(7 \%)$ \\
\hline
\end{tabular}

Table 2: Cost breakdown of screening and blood usage

\begin{tabular}{llll}
\hline $\begin{array}{l}\text { Cost per patient } \\
\text { of group and } \\
\text { screen }\end{array}$ & $\begin{array}{l}\text { Total cost of } \\
\text { group and } \\
\text { screen }\end{array}$ & $\begin{array}{l}\text { Cost per unit of } \\
\text { blood }\end{array}$ & $\begin{array}{l}\text { Total cost of } \\
\text { transfusions (2 } \\
\text { units) }\end{array}$ \\
\hline$£ 35.00$ & $£ 22,470.00$ & $£ 132.72$ & $£ 265.44$ \\
\hline
\end{tabular}

the need for preoperative screening is removed and therefore a reason for potential delay can be avoided.

\section{Conclusion}

To conclude, our study has confirmed that the rate of transfusion in appendicectomy is extremely low, suggesting that the routine use of blood group and antibody screening is unnecessary. Our recommendation would be to crossmatch on an as-required basis and use O-negative where urgent blood is required. The potential cost saving of this practice to our trust would be $£ 22345$, and if this were extrapolated across the NHS, this could be in the region of $£ 1.1 \mathrm{M}$ with very little impact on the demand for O-negative blood.

\section{References}

1. Thomson PM, Ross J, Mukherjee S, et al. Are routine blood group and save samples needed for laparoscopic day case surgery? World J Surg 2016;40(6):1295-1298. DOI: 10.1007/s00268-016-3463-8.

2. Barrett-Lee J, Vatish J, Vazirian-Zadeh M, et al. Routine blood group and antibody screening prior to emergency laparoscopy. Ann R Coll Surg Engl 2018;100(4):322-325. DOI: 10.1308/rcsann.2018.0033.

3. Yazer MH. The blood bank "black box" debunked: Pretransfusion testing explained. CMAJ 2006;174(1):29-32. DOI: 10.1503/cmaj.050919.

4. UK Transfusion guidelines. Joint United Kingdom (UK) Blood Transfusion and Tissue Transplantation Services Professional Advisory Committee, https://www.transfusionguidelines.org/ transfusion-handbook/7-effective-transfusion-in-surgery-andcritical-care/7-3-transfusion-management-of-major-haemorrhage - accessed 24th September 2019.

5. Strobel E. Hemolytic transfusion reactions. Transfus Med Hemother 2008;35(5):346-353. DOI: 10.1159/000154811.

6. NHSBT pricing proposals 2018-2019. Available from https://nhsbtdbe. blob.core.windows.net/umbraco-assets-corp/15273/ncg-pricingproposals-july-board-paper-26-july-2018-v-3-0.pdf [Accessed 8th April 2019].

7. Ko KH, Yoo BH, Kim KM, et al. Frequency of unexpected antibody and consideration during transfusion. Korean J Anesthesiol 2012;62(5):412-417. DOI: 10.4097/kjae.2012.62.5.412.

8. Baird Daniel LH, Constantinos S, Christos K, et al. Acute appendicitis. BMJ 2017;357:j1703. 